\title{
Antileishmanial Acetylene Fatty Acid and Acetogenins from Seeds of Porcelia macrocarpa
}

\author{
Ivanildo A. Brito, ${ }^{\#, a}$ Emerson A. Oliveira, ${ }^{\#, b}$ Mariana H. Chaves, ${ }^{c}$ Fernanda Thevenard, ${ }^{a}$ \\ André F. Rodrigues-Oliveira, ${ }^{\circledR b}$ Gustavo Barbosa-Reis, ${ }^{b}$ Patricia Sartorelli, ${ }^{b}$ Diogo Oliveira-Silva, ${ }^{\odot b}$ \\ Andre G. Tempone, ${ }^{d}$ Thais A. Costa-Silva ${ }^{a}$ and João Henrique G. Lago ${ }^{\circledR} * a$
}

\author{
${ }^{a}$ Centro de Ciências Naturais e Humanas, Universidade Federal do ABC, \\ 09210-580 Santo André-SP, Brazil \\ ${ }^{b}$ Departamento de Química, Instituto de Ciências Ambientais, Químicas e Farmacêuticas, \\ Universidade Federal de São Paulo, 09972-270 Diadema-SP, Brazil \\ 'Departamento de Química, Universidade Federal do Piauí, 64049-550 Teresina-PI, Brazil \\ ${ }^{d}$ Centro de Parasitologia e Micologia, Instituto Adolfo Lutz, 01246-000 São Paulo-SP, Brazil
}

\begin{abstract}
In the present work five acetylene derivatives (1-5), including three unknowns (1, 3 and $\mathbf{4})$, were isolated from seeds of Porcelia macrocarpa (Annonaceae). The structures of isolated compounds were determined as docos-13-yn-21-enoic acid (1), 3-hydroxy-4-methylene-2-(eicos-11'-yn19'-enyl)but-2-enolide (2), 3-hydroxy-4-methylene-2-(octadec-9'-yn-17'-enyl)but-2-enolide (3), 3-hydroxy-4-methylene-2-(hexadec-7'-yn-15'-enyl)but-2-enolide (4), and (2S,3R,4R)-3-hydroxy4-methyl-2-(eicos-11'-yn-19'-enyl)butanolide (5) by analysis of nuclear magnetic resonance (NMR) and electrospray ionization high-resolution mass spectrometry (ESI-HRMS) data. Moreover, all isolated compounds demonstrated selectivity towards intracellular amastigotes of Leishmania (L.) infantum, especially $2-4$ with $50 \%$ inhibitory concentration $\left(\mathrm{IC}_{50}\right)$ values of 9.2, 10.4 and $11.0 \mu \mathrm{M}$, respectively, indicating superior activity of that determined to positive control miltefosine $\left(\mathrm{IC}_{50}\right.$ of $\left.17.8 \mu \mathrm{M}\right)$. Furthermore, these compounds showed higher selectivity index (SI) in comparison with miltefosine. Since related acetylene fatty acid $\mathbf{1}$ displayed reduced antiparasitic potential $\left(\mathrm{IC}_{50}\right.$ of $48.5 \mu \mathrm{M}$ ), the obtained results suggested that the $\gamma$-lactone plays an important role in the antileishmanial activity. However, 2-4 exhibited cytotoxicity to mammalian NCTC cells $\left(\mathrm{CC}_{50}\right.$ ca. $\left.80 \mu \mathrm{M}\right)$, which could be a result of the presence of a conjugated carbonyl system in the lactone ring, since $\mathbf{5}$, the only acetogenin that presents the saturated ring, lacked mammalian cytotoxicity $\left(\mathrm{CC}_{50}>200 \mu \mathrm{M}\right)$.
\end{abstract}

Keywords: Porcelia macrocarpa, acetylene acetogenins, anti-Leishmania (L.) infantum

\section{Introduction}

Leishmaniasis, a parasitic disease caused by protozoa of the genus Leishmania, is common in different sites of tropical and subtropical regions of the world..$^{1,2}$ The chemotherapy for treatment of leishmaniasis consists of usage of toxic compounds discovered more than 50 years ago such as antimonial derivatives, amphotericin B, pentamidine, and miltefosine. ${ }^{3,4}$ Therefore, the search for new compounds to treatment of leishmaniasis is crucial and natural products can be an interesting source of bioactive lead. ${ }^{5}$ The history of drugs against leishmaniasis has a strong

*e-mail: joao.lago@ufabc.edu.br

"Both authors contributed equally to this work. relationship to natural products. Amphotericin B, produced by the Streptomyces nodosus is a leading broad-spectrum antibiotic antifungal and have been used for about 50 years. ${ }^{6}$ Paromomycin, also an anti-leishmanicidal drug, was originally isolated from the bacteria Streptomyces rimosus. ${ }^{7}$ These data show the importance of natural products as a source of bioactive molecules.

Porcelia macrocarpa (Warm.) R. E. Fries (Annonaceae) has been found in the Atlantic Forest region of Brazil. ${ }^{8}$ Different parts of this plant such as leaves, stem bark, and seeds have been chemically studied and shown to be composed of alkaloids, amides/lignanamides, flavonoids, steroids, trimethylamonium salts, amino acids, and acetylene acetogenins. ${ }^{9-14}$ Additionally, the chemical composition of essential oils from its leaves was also investigated and 
the presence of antimicrobial terpenoids was detected. ${ }^{15}$ In previous papers, ${ }^{16-18}$ the occurrence of new acetylene acetogenins and fatty acids from seeds and flowers of P. macrocarpa with anti-T. cruzi activity was reported, including the determination of mechanism of parasite death, which involved alterations in the plasma membrane permeability and electric potential, in the mitochondrial membrane potential as well as in the production of reactive oxygen species (ROS). As a complementary segment of our studies, in the present work five biosynthetic related acetylene derivatives were isolated including one new fatty acid (1), two known (2 and 5) and two new related acetogenins (3 and 4) from seeds of P. macrocarpa. Additionally, the effects of 1-5 against intracellular (amastigote) forms of Leishmania (L.) infantum as well as the toxicity against mammalian cells (NCTC) were evaluated.

\section{Experimental}

\section{General experimental procedures}

Nuclear magnetic resonance (NMR) spectra were recorded on a Bruker (USA) Ultrashield 300 Avance III spectrometer, operating at $300 \mathrm{MHz}$ to ${ }^{1} \mathrm{H}$ and at $75 \mathrm{MHz}$ to ${ }^{13} \mathrm{C}$ nuclei, respectively. $\mathrm{CDCl}_{3}$ (Aldrich, USA) and tetramethylsilane (TMS, Aldrich, USA) were used as the solvent and internal standard. Electrospray ionization high-resolution mass spectrometry (ESI-HRMS) analyses were performed on Bruker (USA) Daltonics micrOTOF-QII mass spectrometer equipped with an Apollo II electrospray ion source operating in negative and positive modes. Silica gel (230-400 mesh, Merck, USA) and Sephadex LH-20 (Amersham Biosciences, UK) were used for column chromatography (CC). For all extraction and chromatography procedures, analytical grade solvents were used (Labsynth Ltd., Brazil).

\section{Plant material}

Fresh seeds of $P$. macrocarpa were collected at Instituto de Botânica de São Paulo in November 2015 (registration code at SisGen A4123E4). As previously reported, ${ }^{18}$ the identification of plant material was performed by Profa Dra Maria Claudia M. Young and a voucher specimen (SP76791) has been deposited in the Herbarium of the Instituto de Botânica (IBT SMA, São Paulo, Brazil).

\section{Extraction and isolation}

Fresh seeds of $P$. macrocarpa were dried at $40{ }^{\circ} \mathrm{C}$ during $72 \mathrm{~h}$ and the obtained plant material (479 g) was powdered and extracted $(4 \times 800 \mathrm{~mL})$ using $n$-hexane. During evaporation of the solvent under reduced pressure was obtained a solid material $(2.7 \mathrm{~g})$ which was separated by filtration. Part of this material $(1.7 \mathrm{~g})$ was chromatographed over silica gel eluted with $n$-hexane containing increasing amounts of EtOAc (up to 100\%) to afford eight fractions (I-VIII). Fraction I (248.3 mg) was subjected to fractionation over Sephadex LH-20 eluted with $n$-hexane: $\mathrm{CH}_{2} \mathrm{Cl}_{2}(1: 4)$ and $\mathrm{CH}_{2} \mathrm{Cl}_{2}$ :acetone $(3: 2$ and $1: 4)$ to afford $30.8 \mathrm{mg}$ of $\mathbf{1}$. Fractions III (1038.2 $\mathrm{mg}$ ) and IV (146.7 $\mathrm{mg}$ ) were found to be composed by pure $\mathbf{5}$ and 2, respectively. Fraction VIII (38.2 mg) was subjected to successive fractionation over Sephadex LH-20 eluted with $n$-hexane: $\mathrm{CH}_{2} \mathrm{Cl}_{2}(1: 4)$ to afford pure $3(1.8 \mathrm{mg})$ and 4 (1.2 mg).

\section{Docos-13-yn-21-enoic acid (1)}

Amorphous solid; ${ }^{1} \mathrm{H}$ NMR $\left(300 \mathrm{MHz}, \mathrm{CDCl}_{3}\right) \delta 5.80$ (ddt, $J 17.0,10.0$ and $6.7 \mathrm{~Hz}, \mathrm{H}-21$ ), 4.95 (m, H-22), 2.27 (t, J 7.0 Hz, H-2), 2.13 (t, J 6.0 Hz, H-12 and H-15), 2.04 (q, $J$ 6.7 Hz, H-19), 1.26 (br s, H-3 to H-11 and H-15 to H-20); ${ }^{13} \mathrm{C} \mathrm{NMR}\left(75 \mathrm{MHz}, \mathrm{CDCl}_{3}\right) \delta 177.2$ (C-1), 139.0 (C-21), 114.1 (C-22), 80.2 (C-13), 80.1 (C-14), * 33.7 (C-2), 33.6 (C-20), 29.4-28.5 (C-4 to C-11 and C-16 to C-19), 24.6 (C-3), 18.7 (C-12 and C-15), *these assignments can be exchanged; ESI-HRMS $m / z$, calcd. for $\mathrm{C}_{22} \mathrm{H}_{37} \mathrm{O}_{2}[\mathrm{M}-\mathrm{H}]^{-}$: 333.2790, found: 333.2791.

3-Hydroxy-4-methylene-2-(octadec-9'-yn-17'-enyl)but2-enolide (3)

White amorphous solid; ${ }^{1} \mathrm{H}$ NMR $\left(300 \mathrm{MHz}, \mathrm{CDCl}_{3}\right)$ $\delta 5.80$ (ddt, $J$ 17.0, 10.0, and $6.7 \mathrm{~Hz}, \mathrm{H}-17^{\prime}$ ), 5.26 (d, $J 2.9$ Hz, H-5a), 5.12 (d, J 2.9 Hz, H-5b), 4.95 (m, H-18'), 2.30 (t, J 7.0 Hz, H-1'a), 2.13 (t, J 6.0 Hz, H-8' and H-11'), 2.04 (q, J 6.7 Hz, H-16'), 1.48 (m, H-1'b), 1.26 (br s, H-2' to $\mathrm{H}-7$ ' and $\mathrm{H}-12$ ' to $\mathrm{H}-15$ '); ${ }^{13} \mathrm{C} \mathrm{NMR}\left(75 \mathrm{MHz}, \mathrm{CDCl}_{3}\right.$ )

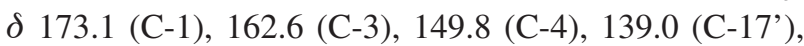
114.2 (C-18'), 105.3 (C-2), 93.1 (C-5), 80.3 (C-9'), * 80.2 (C-10'), *33.7 (C-16'), 31.8 (C-1'), 29.4-28.6 (C-3' to C-7' and C-12' to C-15'), 28.1 (C-2'), 18.7 (C-8' and C-11'), *these assignments can be exchanged; ESI-HRMS $\mathrm{m} / \mathrm{z}$, calcd. for $\mathrm{C}_{23} \mathrm{H}_{33} \mathrm{O}_{3}[\mathrm{M}-\mathrm{H}]^{-}:$357.2430, found: 357.2432.

3-Hydroxy-4-methylene-2-(hexadec-7'-yn-15'-enyl)but2-enolide (4)

White amorphous solid; ${ }^{1} \mathrm{H}$ NMR $\left(300 \mathrm{MHz}, \mathrm{CDCl}_{3}\right)$ $\delta 5.81$ (ddt, $J$ 17.0, 10.0 and $6.7 \mathrm{~Hz}, \mathrm{H}-15^{\prime}$ ), 5.25 (d, $J 2.9$ Hz, H-5a), 5.12 (d, J 2.9 Hz, H-5b), 4.95 (m, H-16'), 2.30 (t, J 7.0 Hz, H-1'a), 2.14 (t, J 6.0 Hz, H-6' and H-9'), 2.05 (q, J 6.7 Hz, H-14'), 1.48 (m, H-1'b), 1.25 (br s, H-2' to $\mathrm{H}-5$ ' and $\mathrm{H}-10$ ' to $\mathrm{H}-13$ '); ${ }^{13} \mathrm{C} \mathrm{NMR}\left(75 \mathrm{MHz}, \mathrm{CDCl}_{3}\right.$ ) 
$\delta 173.1$ (C-1), 162.6 (C-3), 149.8 (C-4), 139.1 (C-15'), 114.2 (C-16'), 105.2 (C-2), 93.0 (C-5), 80.2 (C-7'), * 80.1 $\left(\mathrm{C}^{\prime}{ }^{\prime}\right),{ }^{*} 33.7$ (C-14'), 31.8 (C-1'), 29.4-28.5 (C-3' to C-5' and C-10' to C-13'), 28.1 (C-2'), 18.7 (C-6' and C-9'), *these assignments can be exchanged; ESI-HRMS $\mathrm{m} / \mathrm{z}$, calcd. for $\mathrm{C}_{21} \mathrm{H}_{29} \mathrm{O}_{3}[\mathrm{M}-\mathrm{H}]^{-}: 329.2117$, found: 329.2117 .

\section{Experimental animals}

The experimental animals used in this study, golden hamsters (Mesocricetus auratus) and BALB/c mice, were supplied by the Instituto Adolfo Lutz of São Paulo State, Brazil. The animals received food and water ad libitum and maintained in sterile boxes. Golden hamsters were inoculated every month with amastigotes obtained from the spleen derived of a previously infected hamster, for the maintenance of the $L$. (L.) infantum strain. BALB/c mice were used as a source of peritoneal macrophages. Animal procedures were conducted with the approval of the Ethics Committee of Instituto Adolfo Lutz (project CEUA-IAL/ Pasteur 05/2018) in accordance with the National Institutes of Health (NIH). ${ }^{19}$

Leishmania (Leishmania) infantum parasite, peritoneal macrophages, and NCTC cell culture

L. (L.) infantum parasites (MHOM/BR/1972/LD) were maintained through successive passages in golden hamsters up to 60-70 days after infection. The amount of parasites in the spleen was determined 60-70 days post infection. ${ }^{20}$ Macrophages were obtained from the peritoneal cavity of BALB/c mice by washing with Roswell Park Memorial Institute (RPMI)-1640 medium supplemented with $10 \%$ fetal calf serum (FCS) and kept at $37{ }^{\circ} \mathrm{C}$ in a $5 \% \mathrm{CO}_{2}$-humidified incubator. ${ }^{18}$ Murine fibroblast NCTC cells (clone L929 ATCC) were kept in cell culture flasks in M-199 medium supplemented with $10 \%$ fetal bovine serum (FBS) and $20 \mathrm{mg} \mathrm{mL}^{-1}$ gentamicin at $37^{\circ} \mathrm{C}$ in a $5 \%$ $\mathrm{CO}_{2}$-humidified incubator.

Evaluation of $50 \%$ inhibitory concentration $\left(\mathrm{IC}_{50}\right)$ against amastigote forms of $L$. (L.) infantum

To determine the $\mathrm{IC}_{50}$ concentration against intracellular forms of $L$. (L.) infantum (amastigotes), macrophages collected from the peritoneal cavity of BALB/c mice were counted in a Neubauer chamber, seeded at $1 \times 10^{5}$ per well in a 16-well slide and kept in a $5 \% \mathrm{CO}_{2}$-humidified incubator overnight. Posteriorly, amastigotes were collect from a previously infected hamster as described,$^{20}$ seeded at a ratio 1:10 (macrophages:amastigotes) and maintained at $37{ }^{\circ} \mathrm{C}$ in a $5 \% \mathrm{CO}_{2}$-humidified incubator for $24 \mathrm{~h}$. Subsequently, 1-5 were tested in a range concentration of 100 to $1.56 \mu \mathrm{M}$ with infected macrophages for $96 \mathrm{~h}$. Miltefosine was used as a standard drug. As the last step of the assay, the macrophages were fixed with $\mathrm{MeOH}$, stained with Giemsa (Merck KGaA, Germany), and analyzed on a light microscope. The parasite burden was determined by the number of infected macrophages out of 200 cells.

\section{Cytotoxicity against mammalian cells}

NCTC cells-clone L929 $\left(6 \times 10^{4}\right.$ cells per well $)$ were seeded and incubated with 1-5 $(200-1.56 \mu \mathrm{M})$ for $48 \mathrm{~h}$ at $37^{\circ} \mathrm{C}$ in a $5 \% \mathrm{CO}_{2}$ incubator. The cytotoxic concentration $\left(\mathrm{CC}_{50}\right)$ was determined by MTT (3-(4,5-dimethylthiazol2-yl)-2,5-diphenyltetrazolium bromide) assay. ${ }^{21}$ The optical density was determined in FilterMax F5 (Molecular Devices) at $570 \mathrm{~nm}$. The selectivity index (SI) was determined using the following equation: $\mathrm{CC}_{50}$ against NCTC cells divided by $\mathrm{IC}_{50}$ against parasites. ${ }^{20}$

\section{Statistical analysis}

The results were reported as the mean and standard deviation of duplicate samples from two or three independent assays. $\mathrm{IC}_{50}$ and $\mathrm{CC}_{50}$ values were calculated using sigmoid dose-response curves in Graph Pad Prism 5.0 software, ${ }^{22}$ analysis of variance (ANOVA) for significance $(p<0.05)$.

\section{Results and Discussion}

A sample of the precipitate formed during the evaporation of $n$-hexane extract from seeds of P. macrocarpa was subjected to column chromatography over silica gel and Sephadex LH-20 to afford 1-5 (Figure 1).

Compound 1 was isolated as an amorphous solid. ${ }^{1} \mathrm{H}$ NMR spectrum showed one coupled system at $\delta 5.80$ (ddt, $J 17.0,10.0$ and $6.7 \mathrm{~Hz}$ ) and $4.95(\mathrm{~m}$ ) assigned to hydrogens $\mathrm{H}-21$ and $\mathrm{H}-22$, respectively, one broad singlet at $\delta 1.26$ attributed to the hydrogens of $\mathrm{CH}_{2}$ groups of an aliphatic side chain and two triplets at $\delta 2.13(J 6.0 \mathrm{~Hz}$, $\mathrm{H}-12$ and $\mathrm{H}-15)$ and $2.27(J 7.0 \mathrm{~Hz}, \mathrm{H}-2)$ inferred to adjacent hydrogens of triple bond and carbonyl system, respectively. ${ }^{17} \mathrm{C}$ NMR spectrum revealed three quaternary carbons-one at $\delta 177.2$, assigned to a carbonyl carbon of a carboxylic acid, ${ }^{17,23}$ and two at $\delta 80.2$ and 80.1, typical of acetylene carbons. ${ }^{23,24}$ Besides other peaks, this spectrum also showed signals of $\mathrm{sp}^{2}$ carbons at $\delta 139.0(\mathrm{C}-21)$ and 114.1 (C-22) as well as a $\alpha$-carbonyl carbon at $\delta 33.7$ (C-2). ESI-HRMS showed the $[\mathrm{M}-\mathrm{H}]^{-}$ion at $\mathrm{m} / \mathrm{z}, 333.2791$ 
<smiles>C=CCCCC#CCCCCCC(=O)O</smiles><smiles>C=CCCCC#CCCCCC1=C(O)C(=C)OC1=O</smiles>

$$
2 \mathrm{n}=8
$$$$
3 \mathrm{n}=6
$$$$
4 n=4
$$

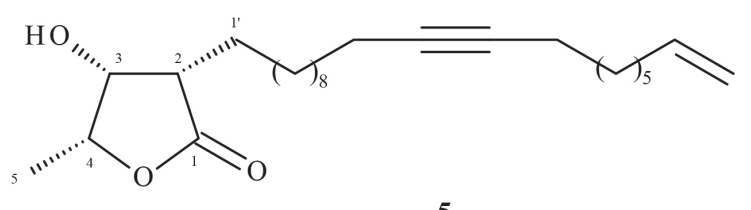

5

Figure 1. Structures of 1-5 isolated from seeds of $P$. macrocarpa.

indicative of a molecular formula $\mathrm{C}_{22} \mathrm{H}_{38} \mathrm{O}_{2}$, regarding four degrees of unsaturation. This spectrum showed also one intense peak at $m / z 249.1856\left[\mathrm{M}-\mathrm{H}-\mathrm{C}_{6} \mathrm{H}_{12}\right]^{-}$referring to fragmentation of the $\mathrm{C}-16 / \mathrm{C}-17$ bond in order to form a conjugated 15-en-13-yn system (Figure 2). Therefore, the position of the triple bond was established at $\mathrm{C}-13$ and the structure of new compound $\mathbf{1}$ was determined as docos13-yn-21-enoic acid.

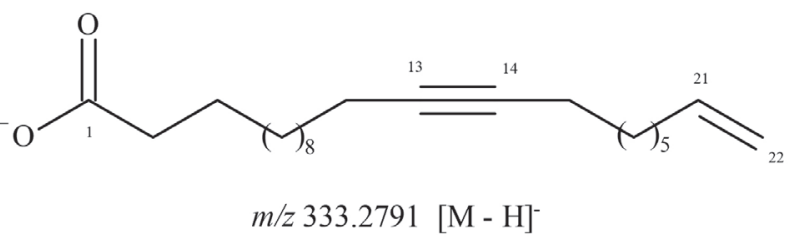
fragmentation at C-16

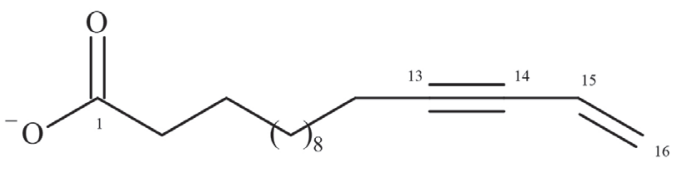

$m / z 249.1856\left[\mathrm{M}-\mathrm{H}-\mathrm{C}_{6} \mathrm{H}_{12}\right]$

Figure 2. Proposed fragmentation in the ESI-HRMS/MS (negative mode) spectrum of $\mathbf{1}$.

Compounds 2-4 were isolated as white amorphous solids and exhibited identical NMR spectra, confirming the occurrence of related compounds. ${ }^{1} \mathrm{H}$ NMR spectra to 2-4 showed signals attributed to olefin hydrogens at $\delta$ 5.80-5.81 (ddt, $J 17.0,10.0$ and $6.7 \mathrm{~Hz}$ ) and $4.95(\mathrm{~m})$ which, associated to the signals attributed to propargyl and allyl hydrogens at $\delta 2.13-2.14(\mathrm{t}, J 6.0 \mathrm{~Hz})$ and 2.04-2.05 $(\mathrm{q}, J 6.7 \mathrm{~Hz}$ ) as well as to one intense broad singlet at $\delta$ 1.25-1.26 (s), suggested the occurrence of an acetylene/ olefin side chain, as previously observed for acetogenins isolated from $P$. macrocarpa. ${ }^{11,18}$ This was confirmed by the presence of two coupled doublets at $\delta 5.25-5.26$ and $5.12(J 2.9 \mathrm{~Hz})$ attributed to the geminal hydrogens $\mathrm{H}-5$ of the lactone ring. In the ${ }^{13} \mathrm{C}$ NMR spectra of $\mathbf{2 - 4}$, besides the signals attributed to $\mathrm{C}-1$ to $\mathrm{C}-5$ of the lactone ring at $\delta 173.1,105.2,162.3,149.8$ and 93.5 , peaks at $\delta 80.3$ and 80.2, assigned to sp carbons, at $\delta 139.0$ and 114.2 to $\mathrm{sp}^{2}$ carbons and several methylene signals ranging from $\delta 32$ to 19 were observed. These data combined with the ESI-HRMS spectrum that showed a $[\mathrm{M}-\mathrm{H}]^{-}$ ion at $\mathrm{m} / \mathrm{z} 385.2744$ lead to the characterization of $\mathbf{2}$ as 3-hydroxy-4-methylene-2-(eicos-11'-yn-19'-enyl)but2-enolide, previously isolated from $P$. macrocarpa. ${ }^{18}$ ESI-HRMS spectra of structurally related $\mathbf{3}$ and $\mathbf{4}$ showed $[\mathrm{M}-\mathrm{H}]^{-}$ions at $m / z 357.2432$ and 329.2117 , respectively, suggesting that $\mathbf{2 - 4}$ are part of a homologous series, since their spectra differ in $28.0316 \mathrm{Da}\left(\mathrm{C}_{2} \mathrm{H}_{4}\right)$. ESI-HRMS/MS data of 2-4 presented a consistent charge retention fragmentation pattern involving hydrogen rearrangement. ${ }^{25}$ The product ions scanning showed $\left[\mathrm{M}-\mathrm{H}-\mathrm{C}_{6} \mathrm{H}_{12}\right]^{-}$ fragments at $\mathrm{m} / \mathrm{z} 301.1806(\mathbf{2}), 273.1494$ (3), and 245.1190 (4) which, in association with fragmentations at positions C-5' ( $m / z$ 179.071), C-7' ( $m / z$ 207.103), and C-9' $(\mathrm{m} / \mathrm{z}$ 235.1336), confirmed the location of the triple bond at C-11', C-9' and C-7', respectively, to $\mathbf{2 ,} 3$ and $\mathbf{4}$. The chain extension between the lactone ring and the triple bond also was supported by the cleavages at C-5' (2-4), C-7' (2 and 3) and C-9' (2). Furthermore, these spectra exhibited a set of intense ions at approximately $\mathrm{m} / \mathrm{z}, 123$ and 137, assigned to fragmentation between lactone ring and side chain, ${ }^{26}$ as shown in Figure 3. Based on these evidences, structures of new acetogenins $\mathbf{3}$ and $\mathbf{4}$ were determined, respectively, as 3-hydroxy-4-methylene-2-(octadec-9'-yn17'-enyl)but-2-enolide and 3-hydroxy-4-methylene2-(hexadec-7'-yn-15'-enyl)but-2-enolide. Compound 5, previously isolated from $P$. macrocarpa was identified as (2S,3R,4R)-3-hydroxy-4-methyl-2-(eicos-11'-yn-19'-enyl) butanolide by comparison of NMR and ESI-HRMS data with those reported in the literature. ${ }^{11}$

P. macrocarpa consists of a source of several natural antiprotozoal products, especially acetylene fatty acids and acetogenins which exhibited anti-T. cruzi potential. ${ }^{17,18}$ However, no information concerning the antileishmanial activity of these related compounds is reported in the literature. Therefore, the anti- $L$. (L.) infantum activity of 1-5 was evaluated against amastigotes forms of this parasite 


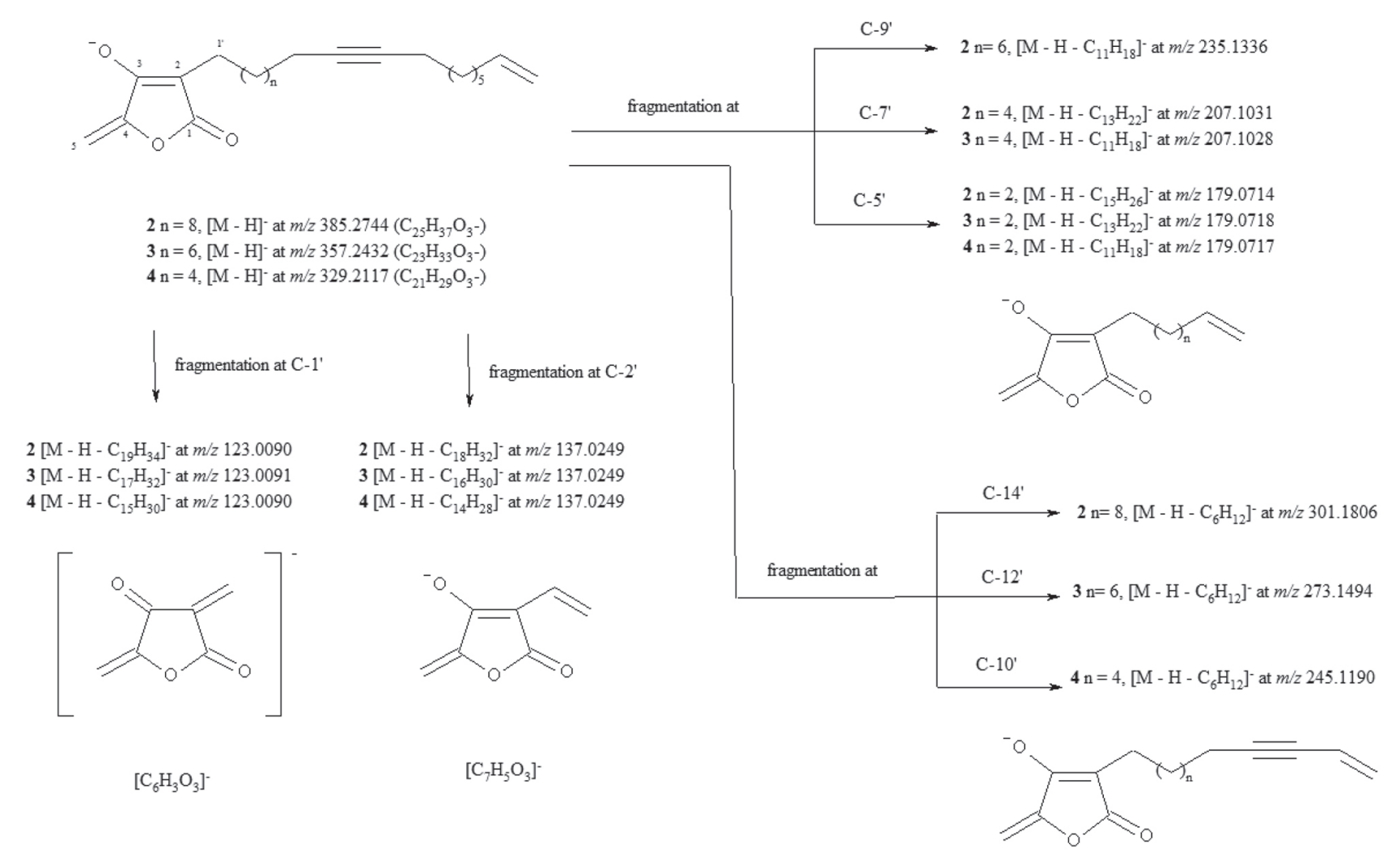

Figure 3. Proposed fragmentation in the ESI-HRMS/MS spectra (negative mode) of 2-4.

while their toxicity was determined against NCTC cells. The results obtained (Table 1) demonstrated that $\mathbf{1}$ and 5 induced no mammalian cytotoxicity in NCTC cells up to the highest tested concentration of $200 \mu \mathrm{M}$, while $\mathbf{2 , 3}$ and 4 exhibited $\mathrm{CC}_{50}$ values of $80.0,82.9$ and $85.4 \mu \mathrm{M}$, respectively. Otherwise, when tested against $L$. infantum amastigotes, isolated 1-5 displayed activity with $\mathrm{IC}_{50}$ values of $48.5,9.2,10.4,11.0$ and $29.9 \mu \mathrm{M}$, respectively, while miltefosine (positive control) showed an $\mathrm{IC}_{50}$ value of $17.8 \mu \mathrm{M}$. The selectivity index (SI), given by ratio between the mammalian toxicity and the activity against the parasite, resulted in values of approximately 8 to all tested acetogenins. Among the tested compounds, it was observed a reduced anti-Leishmania potential for fatty acid $\mathbf{1}$ suggesting the presence of lactone ring is a crucial structural feature associated to antileishmanial activity. Based on this aspect and on the structures of lactones 2-5, some preliminary structure/activity relationships could be established. Initially, it was observed that the effect against the parasite is intensified when a conjugated double bond is present in the lactone ring, as observed for 2-4. Otherwise, as observed for T. cruzi ${ }^{18}$ this structural aspect causes an enhancement in the toxicity to NCTC cells. In a previous study, ${ }^{18}$ acetogenins $\mathbf{2}$ and $\mathbf{5}$ showed activity against other member of the Trypanosomatidae family with $\mathrm{IC}_{50}$ values of 23 and $58 \mu \mathrm{M}$ against amastigotes of T. cruzi. In the present work, no difference in the $\mathrm{IC}_{50}$ values was observed for these compounds, indicating that the extension of side chain did not affect their activity against $L$. (L.) infantum. Therefore, the obtained data suggest that the presence of a lactone associated to the unsaturated carbonyl system appears to be important for the biological activity for related metabolites 2-5 isolated from seeds of P. macrocarpa.

Table 1. Antileishmanial activities of $\mathbf{1 - 5}$, isolated from seeds of P. macrocarpa, against $L$. (L.) infantum

\begin{tabular}{lccc}
\hline Compound & $\mathrm{IC}_{50} / \mu \mathrm{M}$ & $\mathrm{CC}_{50} / \mu \mathrm{M}$ & $\mathrm{SI}$ \\
\hline $\mathbf{1}$ & $48.5 \pm 8.9$ & $>200$ & 4.1 \\
$\mathbf{2}$ & $9.2 \pm 3.2$ & $80.0 \pm 27.0$ & 8.7 \\
$\mathbf{3}$ & $10.4 \pm 5.6$ & $82.9 \pm 11.6$ & 8.0 \\
$\mathbf{4}$ & $11.0 \pm 2.0$ & $85.4 \pm 10.5$ & 7.8 \\
$\mathbf{5}$ & $29.9 \pm 9.7$ & $>200$ & $>6.7$ \\
Miltefosine & $17.8 \pm 1.4$ & $116.0 \pm 5.3$ & 6.5 \\
\hline
\end{tabular}

$\mathrm{IC}_{50}: 50 \%$ inhibitory concentration; $\mathrm{CC}_{50}: 50 \%$ cytotoxic concentration (NCTC cells); SI: selectivity index.

Natural acetylene derivatives, especially acetogenins, are found in several species of Annonaceae. ${ }^{27}$ Considering the structures of these compounds, especially those which contains tetrahydrofuran (THF) moiety in the side chain, important structural factors were established. As previously 
reported, ${ }^{28,29}$ the presence of THF groups was favorable, but not essential, for the activity. On the other hand, the presence of long alkyl tail could be considered an essential structural requirement for the activity. ${ }^{30}$ Another study ${ }^{31}$ reported that the $\gamma$-lactone ring, a common structural unit among a large number of natural acetogenins, plays an important role in the anti-Leishmania potential, especially those which contains $\alpha, \beta$-unsaturated system, but it is not crucial to the activity. Therefore, due to their important pharmacological potential, including antiprotozoal activity, ${ }^{29}$ Annonaceae acetogenins have been considered an important source of new prototypes for development of new drugs against Leishmania (L.) infantum.

\section{Conclusions}

This work reports the isolation and chemical characterization of five biosynthetically related compounds from seeds of $P$. macrocarpa, with one being a fatty acid (1) and four acetogenins (2-4). The occurrence of acetylene acetogenins $\mathbf{2}$ and $\mathbf{5}$ was previously reported in $P$. macrocarpa but this is the first description of $\mathbf{1}, \mathbf{3}$ and 4. The anti-leishmanial activities of 1-5 indicated that acetogenins 2-4 showed superior potential than positive control miltefosine. However, acetogenin 5, which did not display an unsaturated carbonyl system in the lactone ring, displayed reduced potential. Fatty acid 1, which showed a similar acetylene/olefin side chain compared to $\mathbf{2}$ and $\mathbf{5}$, but with absence of lactone ring, exhibited reduced potential. Despite related compounds displayed anti-T. cruzi activity, this work describes for the first time their antileishmanial activity demonstrating the potential of these compounds in the search for new drug candidates for neglected diseases.

\section{Supplementary Information}

Supplementary data (NMR and ESI-HRMS spectra for 1-5) are available free of charge at http://jbcs.sbq.org. br as PDF file.

\section{Acknowledgments}

Authors are thankful for the financial support and fellowships provided by Coordenação de Aperfeiçoamento de Pessoal de Nível Superior-Brasil (CAPES, finance code 001), Conselho Nacional de Desenvolvimento Científico e Tecnológico (CNPq, for grants to O. S., A. G. T. and J. H. G. L.) and to Fundação de Amparo à Pesquisa do Estado de São Paulo (FAPESP 2018/07885-1 and 2018/10279-6). This publication is part of the activities of the Research Network Natural Products against Neglected Diseases (ResNetNPND).

\section{Author Contributions}

I. A. B. was responsible for experimental work, data collection and evaluation, literature search and manuscript preparation, investigation; E. A. O. for experimental work, data collection and evaluation, literature search and manuscript preparation; M. H. C. for spectral analysis and interpretations, writing review and editing; F. T. for data curation, writing review and editing; A. F. R. O. for experimental work, data collection and evaluation; G. B. R. for spectral analysis and interpretations; P. S. for spectral analysis and interpretations; D. O. S. for spectral analysis and interpretations, writing review and editing; A. G. T. for funding acquisition, writing review and editing; T. A. C. S. for experimental work, data collection and evaluation; J. H. G. L. for experimental work, data collection and evaluation, conceptualization, literature search and manuscript preparation, data curation, funding acquisition, project administration, spectral analysis and interpretations, writing original draft, writing review and editing.

\section{References}

1. http://www.who.int/neglected_diseases/diseases/en/, accessed in September 2020.

2. http://www.who.int/leishmaniasis/en/, accessed in September 2020.

3. Sundar, S.; Chakravarty, J.; Expert Opin. Pharmacother. 2015, 16, 237.

4. Menezes, J. P. B.; Guedes, C. E. S.; Petersen, A. L. O. A.; Fraga, D. B. M.; Veras, P. S. T.; BioMed Res. Int. 2015, 815023.

5. Moore, E. M.; Lockwood, D. N.; J. Global Infect. Dis. 2010, 2,151 .

6. Murphy, B.; Anderson, K.; Borissow, C.; Caffrey, P.; Griffith, G.; Hearn, J.; Ibrahim, O.; Khan, N.; Lamburn, N.; Lee, M.; Pugh, K.; Rawlings, B.; Org. Biomol. Chem. 2010, 21, 3758.

7. Botero, D.; Annu. Rev. Pharmacol. Toxicol. 1978, 18, 1.

8. Murray, N. A.; Syst. Bot. Monogr. 1993, 40, 8.

9. Chaves, M. H.; Santos, L. A.; Lago, J. H. G.; Roque, N. F.; J. Nat. Prod. 2001, 64, 240.

10. Lago, J. H. G.; Chaves, M. H.; Ayres, M. C. C.; Agripino, D. G.; Young, M. C. M.; Planta Med. 2007, 73, 292.

11. Chaves, M. H.; Roque, N. F.; Phytochemistry 1997, 44, 523.

12. Chaves, M. H.; Roque, N. F.; Phytochemistry 1997, 46, 879.

13. Chaves, M. H.; Roque, N. F.; Ayres, M. C. C.; J. Braz. Chem. Soc. 2004, 15, 608.

14. Chaves, M. H.; Freitas, A.; Roque, N. F.; Cavalheiro, A. J.; Quim. Nova 2000, 23, 307. 
15. Silva, E. B.; Soares, M. G.; Mariane, B.; Vallim, M. A.; Pascon, R. C.; Sartorelli, P.; Lago, J. H. G.; Molecules 2013, 18, 13574.

16. Santos, L. A.; Cavalheiro, A. J.; Tempone, A. G.; Correa, D. S.; Alexandre, T. R.; Quintiliano, N. F.; Rodrigues-Oliveira, A. F.; Oliveira-Silva, D.; Martins, R. C. C.; Lago, J. H. G.; Molecules 2015, 20, 8168.

17. Londero, V. S.; Costa-Silva, T. A.; Gomes, K. S.; Ferreira, D. D.; Mesquita, J. T.; Tempone, A. G.; Young, M. C. M.; Jerz, G.; Lago, J. H. G.; Bioorg. Chem. 2018, 78, 307.

18. Oliveira, E. A.; Brito, I. A.; Lima, M. L.; Romanelli, M.; Moreira-Filho, J. T.; Neves, B. J.; Andrade, C. H.; Sartorelli, P.; Tempone, A. G.; Costa-Silva, T. A.; Lago, J. H. G.; J. Nat. Prod. 2019, 82, 1177.

19. National Institutes of Health (NIH); Guide for the Care and Use of Laboratory Animals, $8^{\text {th }}$ ed.; The National Academies Press: Washington, 2011, available at https://grants.nih.gov/ grants/olaw/guide-for-the-care-and-use-of-laboratory-animals. pdf, accessed in September 2020.

20. Grecco, S. S.; Costa-Silva, T. A.; Sousa, F. S.; Cargnelutti, S. B.; Umehara, E.; Mendonça, P. S.; Tempone, A. G.; Lago, J. H. G.; J. Venomous Anim. Toxins Incl. Trop. Dis. 2018, 24, 27.

21. Tada, H.; Shiho, O.; Kuroshima, K.; Koyama, M.; Tsukamoto, K.; J. Immunol. Methods 1986, 93, 157.

22. GraphPad Prism, version 5.0; GraphPad Software Inc., San Diego, USA, 2018.
23. Li, X. C.; Jacob, M. R.; Khan, S. I.; Ashfaq, M. K.; Babu, K. S., Agarwal, A. M.; ElSohly, H. N.; Manly, S. P.; Clark, A. M.; Antimicrob. Agents Chemother. 2008, 52, 2442.

24. Quinoa, E.; Crews, P.; Tetrahedron Lett. 1987, 28, 2467.

25. Demarque, D. P.; Crotti, A. E. M.; Vessecchi, R.; Lopes, J. L. C.; Lopes, N. P.; Nat. Prod. Rep. 2016, 33, 432.

26. Madeira, P. J.; Rosa, A. M.; Xavier, N. M.; Rauter, A. P.; Florêncio, M. H.; Rapid Commun. Mass Spectrom. 2010, 24, 1049.

27. Liaw, C. C.; Liou, J. R.; Wu, T. Y.; Chang, F. R.; Wu, Y. C.; Prog. Chem. Org. Nat. Prod. 2016, 101, 113.

28. Raynaud-Le Grandic, S.; Fourneau, C.; Laurens, A.; Bories, C.; Hocquemiller, R.; Loiseau, P. M.; Biomed. Pharmacother. 2004, 58, 388.

29. Schmidt, T. J.; Khalid, S. A.; Romanha, A. J.; Alves, T. M.; Biavatti, M. W.; Brun, R.; Costa, F. B.; Castro, S. L.; Ferreira, V. F.; Lacerda, M. V.; Lago, J. H. G.; Leon, L. L.; Lopes, N. P.; Amorim, R. C. N.; Niehues, M.; Ogungbe, I. V.; Pohlit, A. M.; Scotti, M. T.; Setzer, W. N.; Soeiro, M. N. C.; Steindel, M.; Tempone, A. G.; Curr. Med. Chem. 2012, 19, 2176.

30. Motoyama, T.; Yabunaka, H.; Miyoshi, H.; Bioorg. Med. Chem. Lett. 2002, 12, 2089.

31. Takada, M.; Kuwabara, K.; Nakato, H.; Tanaka, A.; Iwamur, H.; Miyoshi, H.; Biochim. Biophys. Acta 2000, 1460, 302.

Submitted: May 20, 2020 Published online: October 2, 2020 